\title{
DESIGNING A SUPPLY CHAIN MODEL WITH CONSIDERATION DEMAND FORECASTING AND INFORMATION SHARING
}

\author{
S.M.T. Fatemi Ghomi and N. Azad \\ Department of Industrial Engineering \\ Amirkabir University of Technology, Iran \\ fatemi@aut.ac.ir
}

\begin{abstract}
In traditional supply chain inventory management, orders are the only information firms exchange, but information technology now allows firms to share demand and inventory data quickly and inexpensively. To have an integrated plan, a manufacturer not only needs to know demand information from its customers but also supply information from its suppliers. In this paper, information flow is incorporated in a three-echelon supply chain model. Also to decrease the risk of the supply chain system, the customers' demands are predicted first and this prediction is then used as an input to the supply chain model. In this paper a proposed evolving fuzzy predictor model will be used to predict the customers' demands. For solving the supply chain model, a hybrid heuristic combining tabu search with simulated annealing sharing the same tabu list is developed.
\end{abstract}

\section{OPSOMMING}

In tradisionele voorsieningskettingvoorraadbestuur verteenwoordig bestellings die enigste vorm van van inligting wat deur ondernemings uitgeruil word. Inligtingstegnologie laat ondernemings egter deesdae toe om vraag- en voorraadata vinnig en goedkoop uit te ruil. Om 'n geïntegreerde plan te hê, het 'n vervaardiger nie alleen aanvraaginligting nodig van sy klante nie, maar ook aanbodinligting van sy leweransiers. In hierdie artikel word inligtingvloei geinkorporeer in 'n drie-vlakvoorsieningskettingmodel. Voorts, om die risiko in die voorsieningskettingmodel te verminder, word die klante se aanvraag eers vooruitgeskat en die vooruitskatting word dan gebruik as 'n inset tot die model. Hierdie artikel gebruik 'n groeiende wasige vooruitskattingsmodel om die klantebehoeftes voor uit te skat. Om die model op te los, word ' $n$ hibriede heuristiese metode gekombineer met ' $n$ "tabu"-soektog gebruik. 


\section{INTRODUCTION}

The performance of a supply chain depends critically on how its members coordinate their decisions. Information sharing between supply chain partners is a prerequisite for coordinated supply chain management. Over the last few years, considerable research has been devoted to understanding the role of information in achieving supply chain coordination. The research of information sharing in supply chain grew largely out of twostage inventory models. The following papers mainly examine what kind of benefit can be gained through demand-oriented information sharing: Gavirneni et al. [1], Lee et al. [2]. Further studies that analyze the benefit of information sharing with multiple retailers are as follows: Cachon and Fisher [3], Gavirneni [4], Aviv and Federgruen [5]. Other researchers investigated forecasting information sharing. Cachon and Lariviere [6] studied forecast sharing in a single product, two-level supply chain. Aviv [7] compared three settings under a two-level supply chain. Zhao et al. [8] presented the impact of different forecasting models on the value of information sharing in a supply chain.

Previous research mainly focused on two-stage supply chain models and explored the impact of demand-oriented information sharing, such as forecasting, inventory, and order information sharing. Although two-stage models can help in describing basic supply chain phenomena, these models clearly do not capture many complex characteristics involved in real world supply chains. A complete supply chain process model should include source, make and deliver from suppliers to customers under the coverage of an integrated plan. On the other hand, to have an integrated plan, a manufacturer not only needs to know demand information from its customers but also supply information from its suppliers. Therefore, a three-level supply chain model will be established that includes sources, make and deliver processes to examine the effect of supply information sharing, also to predict the customer's demands in the supply chain system. The forecast of future demand forms the basis for all strategic and planning decisions in a supply chain. In the literature several techniques have addressed time series prediction [9]. Stochastic models and dynamic-based techniques are the main classical techniques reported in literature [10]. However, these techniques are found to underperform in predicting the behavior of complex systems. Alternative approaches have been investigated by many researchers. These approaches use computational intelligence techniques such as Neural Networks, Neuro-Fuzzy and Evolutionary Fuzzy Systems [11-15]. In recent years, more attention has been paid to learning and adaptive systems integrated with computational intelligence techniques. Evolving predictive systems capable of updating the parameters and structure simultaneously are proposed in [16-18].

This paper proposes an evolving fuzzy predictor (EFP) model for forecasting the customers' demands in the supply chain system. When the customers' demand is predicted, then it is used as an input to the proposed supply chain model. For solving the supply chain model, a hybrid heuristic combining tabu search with simulated annealing (SA) sharing the same tabu list is developed.

The reminder of the paper is organized as follows. Section 2 discusses the proposed evolving fuzzy predictor EFP model and ARMA model. Section 3, presents the mathematical formulation of the supply chain model. Section 4 discusses the solution approach to the problem. Section 5 discusses some computational results. Finally, section 6 contains some conclusions and future research development.

\section{PREDICTION TECHNIQUES}

The goal of the prediction task is to use past values of time series to the time $t$ to predict the values at some point in the future $t+\delta$. A mapping from $p$ points of the time series spaced $\Delta$ apart is created to predict future value $\hat{x}(t+\delta)$.

$[x(t-(p-1) \Delta) \ldots x(t-(p-j) \Delta) \ldots x(t-\Delta) x(t)] \Rightarrow \hat{x}(t+\delta)$ 
This paper proposes an evolving fuzzy predictor (EFP) model to predict the demand time series. The prediction results of demand time series are also compared with the well established technique of Auto Regressive Moving Average (ARMA) model [19, 20].

The following two sub sections give more details about EFP model as well as ARMA model.

\subsection{Evolving Fuzzy Predictor Model}

To predict the demand time series $x(t)$, the current and past values of the signal are modeled as rules that represent the nonlinear relationship between these values. A fuzzy rule of the following form will be used as the model for prediction of the demand time series:

$R_{i}$ : If $x(t)$ is $\widetilde{A}_{i}^{p} \ldots$ and $x(t-(p-j) \Delta)$ is $\tilde{A}_{i}^{j} \ldots$ and $x(t-(p-1) \Delta)$ is $\widetilde{A}_{i}^{1}$ then $x(t+\delta)$ is $B_{i}$

where $R_{i}$ is the label of $i$ - th rule, $x(t-(p-j) \Delta): j=1, \ldots, p$ is the $j$-th input, $x(t+\delta)$ is the output, $\widetilde{A}_{i}^{j}(i=1, . ., n$ and $j=1, \ldots, p)$ is a fuzzy label, and $B_{i}$ is either a real number or a linear combination of inputs $B_{i}=q_{0 i}+q_{1 i} \times x(t)+\ldots+q_{p i} \times x(t-(p-1) \Delta) . n$ and $p$ are the number of rules and number of individual inputs respectively.

The decision $\hat{x}(t+\delta)$ for the $i$-th instance, as a function of inputs $x(t-(p-j) \Delta): j=1, \ldots, p$, is given in the following equation:

$$
\hat{x}(t+\delta)=\frac{\sum_{i=1}^{n} w_{i} B_{i}}{\sum_{i=1}^{n} w_{i}}
$$

where $B_{i}$ are the consequent parameters and $w_{i}$ is the rule firing strength given by:

$$
w_{i}=\prod_{j=1}^{p} \mu_{\widetilde{A}_{i}^{j}}(x(t-(p-j) \Delta)) i=1, \ldots, n
$$

where $\mu_{\widetilde{A}_{i}^{j}}$ is the membership function (MF) of the fuzzy value $\widetilde{A}_{i}^{j}$. Gaussian membership functions with two parameters $\rho_{i}^{j}$ and $\sigma_{i}^{j}$ as the mean and spread of MFs are considered.

$$
\mu_{\widetilde{A}_{i}^{j}}(x(t-(p-j) \Delta))=\exp \left(-\left(\frac{x(t-(p-j) \Delta)-\rho_{i}^{j}}{\sigma_{i}^{j}}\right)^{2}\right)
$$

In short, the parameters of a fuzzy rule-based system are defined as $\theta_{i j}=\left(\rho_{i}^{j}, \sigma_{i}^{j}, B_{i}\right)$. The prediction problem is now in the form of identifying the parameters of the rule base, $\theta_{i j}$. Starting from the initial values of the parameters, to update these parameters as more data is available, the adaptation technique presented in the next section can be employed. 


\subsubsection{Predictor Model Adaptation}

To minimize the difference between the predicted demand time series $\hat{x}(t+\delta)$ and actual demand time series $x(t+\delta)$, the error generated from all data must be minimized.

The following mean square error function is considered to minimize the prediction error.

$$
E(\Theta)=\frac{1}{2} \sum_{k=1}^{s} e_{k}^{2}\left(\theta_{i j}\right)=\frac{1}{2} \sum_{k=1}^{s}(x(t+\delta)-\hat{x}(t+\delta))^{2}
$$

where $e_{k}$ is the difference between the actual value, $x(t+\delta)$, and the predicted value, $\hat{x}(t+\delta)$, for the $k$-th training data sample. It is assumed that there is a total of $s$ samples in the training data set.

All parameters of the fuzzy predictor model, $\theta_{i j}=\left(\rho_{i}^{j}, \sigma_{i}^{j}, B_{i}\right)$ can be updated using a steepest gradient descent method to minimize the error function $E(\Theta)$ given in expression (6). The parameters will then be updated by the following rule:

$\left.\theta_{i j}\right|_{\text {new }}=\left.\theta_{i j}\right|_{\text {old }}-\lambda \times \nabla e_{i j}$

where $\nabla e_{i j}$ is the gradient of parameters and $\lambda$ is the rate of descent which may be chosen arbitrarily.

The partial derivative of the error function, $E(\Theta)$ with respect to each parameter is given by:

$$
\nabla e_{i j}=\left[\frac{\partial E}{\partial \rho_{i}^{j}}, \frac{\partial E}{\partial \sigma_{i}^{j}}, \frac{\partial E}{\partial B_{i}}\right]
$$

Where

$$
\begin{aligned}
\frac{\partial E}{\partial B_{i}} & =-\frac{e_{k} w_{i}}{\sum_{i=1}^{n} w_{i}} \\
\frac{\partial E}{\partial \rho_{i}^{j}} & =-\frac{2 e_{k} w_{i}\left(B_{i}-x(t+\delta)\right)\left(\frac{x(t-(p-j) \Delta)-\rho_{i}^{j}}{\sigma_{i}^{j}}\right)^{2}}{\left(x(t-(p-j) \Delta)-\rho_{i}^{j}\right) \sum_{i=1}^{n} w_{i}} \\
\frac{\partial E}{\partial \sigma_{i}^{j}} & =-\frac{2 e_{k} w_{i}\left(B_{i}-x(t+\delta)\right)\left(\frac{x(t-(p-j) \Delta)-\rho_{i}^{j}}{\sigma_{i}^{j}}\right)^{2}}{\sigma_{i}^{j} \sum_{i=1}^{n} w_{i}}
\end{aligned}
$$


It is anticipated that when the parameters are adapted, the prediction error will be reduced. The gradient descent technique given above suffers from various convergence problems. This has been investigated by many researchers. The convergence problem of the steepest descent technique in fuzzy inference systems modeling is discussed in [21].

It is reasonable to take large steps down the gradient at locations where the gradient is small and small steps where the gradient is large.

The customer's demands are predicted for each product in each period and the prediction is used as an input to the supply chain model.

\subsection{Auto Regressive Moving Average}

This technique is used as a basis for the analysis and it is a well established technique in the prediction of time series. An ARMA model has two parameters, $p$ and $q$. The first parameter is the auto regression parameter and the second parameter is the moving average parameter. Hence an ARMA process $x(t)$ can be presented as follows:

$$
x(t)-\phi_{1} x(t-1)-\ldots-\phi_{p} x(t-p)=\varepsilon(t)-\theta_{1} \varepsilon(t-1)-\ldots-\theta_{q} \varepsilon(t-q)
$$

where $\varepsilon(t)$ is the white noise with mean 0 and variance $\sigma^{2}, \phi$ is the coefficient of the auto regression part, and $\theta$ is the coefficient of the moving average part. Expression (12) can be formulated as:

$$
x(t)=\varepsilon(t)+\sum_{i=1}^{p} \phi_{i} x(t-i)-\sum_{j=1}^{q} \theta_{j} \varepsilon(t-j)
$$

The polynomials $\phi$ and $\theta$ will be referred to as the autoregressive and moving average polynomials respectively.

\section{THE SUPPLY CHAIN MODEL}

Suppose there are several capacitated suppliers, one manufacturer and several retailers. The retailers are confronted with time-varying customer demands, which were predicted in the previous section. In the proposed supply chain model, the local manufacturer faces its retailers' demands and purchases materials from its suppliers. The suppliers are end suppliers; that is to say, they do not need to order raw materials from other suppliers to make their own products. Each supplier can supply one material. The manufacturer produces several products.

The production planning of the manufacturer is a multi-product multi-constrained resource lot sizing problem. The sequence of events in every period is as follows. Firstly, the manufacturer decides on his production quantity for the period, and the materials needed are transported from suppliers under the resources constraints. Next, the manufacturer consigns his products to several retailers. If the manufacturer cannot satisfy the full order of the retailer, it is assumed that the retailer acquires the shortage part of the order elsewhere. Everything takes place with no lead time. Subsequently customer demands occur. Lastly inventory holding or shortage penalty costs are charged.

The following introduces some indices and parameters, which will be used in the formulas and models are as follows:

Indices: 
$l: \quad$ Product index, $l=1, \ldots, L$;

$n$ : $\quad$ Supplier index, $n=1, \ldots, N$;

$m: \quad$ Retailer index, $m=1, \ldots, M$;

$t: \quad$ Index of planning period, $t=1, \ldots, T$;

Parameters:

$a_{n l t}$ : Capacity needed on material $n$ for one unit product $l$ in period $t$;

$R_{n t}$ : The supplier capacity of available material $n$ in period $t$;

$b_{n}$ : Unit transportation cost for material $n$ to the manufacturer;

$c_{l t}$ : Unit production cost for product $l$ in period $t$;

$h_{l t}$ : Unit inventory holding cost for product $l$ in the manufacturer in period $t$;

$g_{l m}: \quad$ Unit transportation cost for product $l$ to the retailer $m$;

$h_{l t m}$ : Unit inventory holding cost for product $l$ in the retailer $m$ in period $t$;

$\beta$ : The penalty coefficient for the shortage of the manufacturer to the retailer;

$D_{l t m}$ : The predicted customer demand for product $l$ in retailer $m$ in the period $t$;

Variables:

$I_{l t}$ : The inventory of product $l$ in the manufacturer at the end of period $t$;

$I_{l t m}: \quad$ The inventory of product $l$ in the retailer $m$ at the end of period $t$;

$O_{l t m}$ : The shortage of product $l$ for the retailer $m$ from the manufacturer in the period $t$;

Decision variables:

$X_{l t}$ : The amount of product $l$ produced in period $t$;

$f_{l t m}: \quad$ The quantities of product $l$ distributed to the retailer $m$ in period $t$.

The total cost of the supply chain can be formulated as follows:

$C(X, f)=\sum_{n=1}^{N} \sum_{l=1}^{L} \sum_{t=1}^{T} b_{n} a_{n l t} X_{l t}+\sum_{l=1}^{L} \sum_{t=1}^{T}\left(c_{l t} X_{l t}+h_{l t} I_{l t}\right)+\sum_{m=1}^{M} \sum_{l=1}^{L} \sum_{t=1}^{T}\left(g_{l m} f_{l t m}+h_{l t m} I_{l t m}+\beta O_{l t m}\right)$

Thus the problem can be formulated as follows:

$\operatorname{MIN} \quad C(X, f)$

Subject to:

$\sum_{l=1}^{L} a_{n l t} X_{l t} \leq R_{n t} \quad$ for all $n, t$ 


$$
\begin{aligned}
& I_{l, t-1}+X_{l t}-I_{l t}=\sum_{m=1}^{M} f_{l t m} \quad \text { for all } l, t \\
& I_{l, t-1, m}+f_{l t m}-I_{l t m}+O_{l t m} \geq D_{l t m} \quad \text { for all } l, t, m \\
& X_{l t} \geq 0 \quad \text { for all } l, t \\
& f_{l t m} \geq 0 \quad \text { for all } l, t, m \\
& I_{l t} \geq 0 \quad \text { for all } l, t \\
& I_{l t m} \geq 0 \quad \text { for all } l, t, m \\
& O_{l t m} \geq 0 \quad \text { for all } l, t, m
\end{aligned}
$$

Constraint (16) is the total capacity for a material $n$ needed to produce all the scheduled products in period $t$. Constraint (17) defines the quantities of product $l$ on consignment by the manufacturer for the retailers in period $t$. Constraint (18) is to satisfy the customer demands. Constraints (19)-(23) enforce the non-negativity restrictions on the corresponding variables.

\section{SOLUTION APPROACH}

A hybrid heuristic combining simulated annealing with tabu search sharing the same tabu list is used to solve the large-sized problems.

The parameters for the hybrid tabu-SA algorithm are as follows:

$T_{0}: \quad$ Initial temperature,

$C: \quad$ Rate of the current temperature decreases (cooling schedule),

$S T: \quad$ Freezing temperature (the temperature at which the desired energy level is reached),

$X: \quad$ A feasible solution

$C(X)$ : The value of objective function for $X$,

The steps of proposed hybrid tabu-SA based heuristic are as follows:

Step1: $\quad X_{\text {best }}=\phi, \quad$ select an initial solution, $\left(X_{0}\right)$

$$
X_{\text {best }}=X_{0}, X=X_{0}
$$

Step2: Generate solution $X_{n}$ in the neighborhood of $X$.

Step3: Is the candidate moved in the tabu list? If yes, go to Step 4. Otherwise go to Step 5.

Step4: If $C\left(X_{n}\right) \leq C\left(X_{\text {best }}\right)$ then $X=X_{n}, X_{\text {best }}=X_{n}$, update the tabu list and go to Step 6. Otherwise go to step 2 to choose another candidate move.

Step5: Let $\Delta C=C\left(X_{n}\right)-C(X)$.

5.1. If $\Delta C \leq 0$ then $X=X_{n}, r=r+1$, update the tabu list and if 


$$
C\left(X_{n}\right)<C\left(X_{\text {best }}\right) \text { then } X_{\text {best }}=X_{n} \text {. }
$$

5.2. If $\Delta C>0$ then $y \rightarrow U(0,1), z=e^{-\frac{\Delta C}{T_{0}}}$. If $y<z$ then $X=X_{n}$.

Step6: Should the procedure stop under temperature $T_{0}$ ? If yes, go to Step 7. Otherwise go to Step 2. When the number of accepted solutions under temperature $T_{0}$ reaches a predefined value, the following condition should be checked:

$$
\frac{\left|A O V_{c}-A O V_{b}\right|}{A O V_{b}} \leq \varepsilon
$$

where $A O V_{c}$ is the average objective value of accepted solutions under the temperature $T_{0}, A O V_{b}$ is the average objective value of accepted solutions before the temperature $T_{0}, \varepsilon$ is a predefined equilibrium value $(0<\varepsilon<1)$. If the above condition is satisfied, the procedure stops under temperature $T_{0}$. This condition was proposed by Skiscim and Golden [22].

Step7: $T_{0}=C \times T_{0}$.

Step8: Is the stopping criterion ( $T_{0}<S T$ ) matched? If yes, stop. Otherwise, go to Step 2.

Fig.1. shows the steps of proposed tabu-SA algorithm.

$$
X_{\text {best }}=\phi
$$

Select an initial solution, $X_{0}$

$$
X_{\text {best }}=X_{0}, X=X_{0}
$$

While ( $T_{0}<S T$ ) Do

While $\left(\frac{\left|A O V_{c}-A O V_{b}\right|}{A O V_{b}} \leq \varepsilon\right)$ Do

Generate solution $X_{n}$ in the neighborhood of $X$,

$$
\Delta C=C\left(X_{n}\right)-C(X)
$$

If the candidate move is in the tabu list, then

If $C\left(X_{n}\right)<C\left(X_{\text {best }}\right)$ then

$$
X=X_{n}, X_{\text {best }}=X_{n} \text {, update the tabu list }
$$

Else

Generate another solution $X_{n}$ in the neighborhood of $X$

End If

Else 


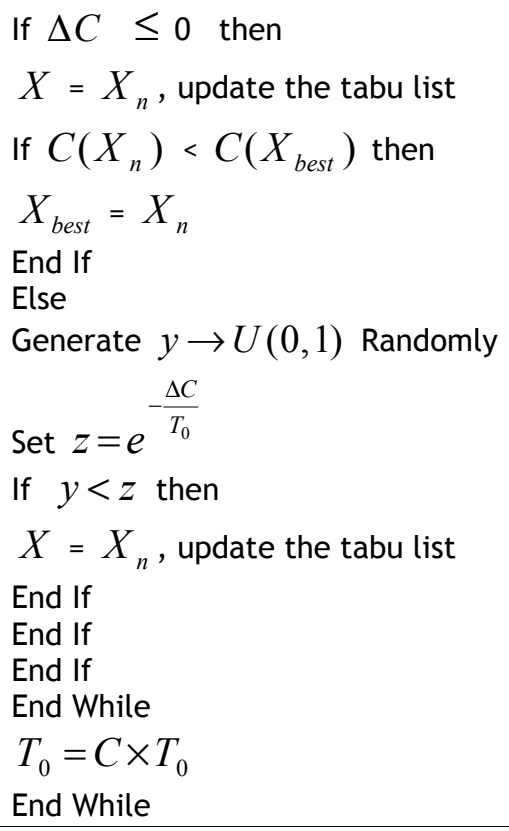

Figure 1: Proposed hybrid tabu-SA algorithm

Subsections 4.1 and 4.2, describe the initial solution construction and generating the candidate move which used for the hybrid tabu-SA algorithm.

\subsection{Representation and Initialization}

The procedure to obtain the initial solution is random. The decision variables of the problem are $X_{l t}$ and $f_{l t m}$, they are positive variables of real numbers. Variables $X_{l t}$ and $f_{\text {ltm }}$ as follows:

$$
\begin{aligned}
(X, f)= & \left(X_{11}, X_{12}, \ldots, X_{1 T}, X_{21}, X_{22}, \ldots, X_{2 T}, \ldots, X_{L 1}, X_{L 2}, \ldots, X_{L T},\right. \\
& \left.f_{111}, f_{112}, \ldots, f_{11 M}, \ldots, f_{2 T 1}, f_{2 T 2}, \ldots, f_{2 T M}, \ldots, f_{L T 1}, f_{L T 2}, \ldots, f_{L T M}\right)
\end{aligned}
$$

For a capacitated lot-sizing problem, the decision variables $X_{l t}$ are dependent on the available resources capacities $R_{n t}$. In this situation, it is first checked whether the total capacity for a resource needed to produce all the scheduled products in a period exceeds the total available capacity for this resource at this period. If it exceeds, another solution is generated to replace it.

\subsection{Obtaining the candidate move}

To obtain the candidate move, randomly select one $X_{l t}$ in $X$ part of the solution and regenerate its value. Then adjust the correlative value of $f$ of the solution according to the replacement and check its feasibility.

\section{COMPUTATIONAL RESULTS}

This section describes the computational experiments designed to evaluate the performance of the evolving fuzzy predictor and the hybrid tabu-SA algorithm which was conducted with respect to a series of test problems. 
The hybrid tabu-SA algorithm was coded in visual Basic 6 and run on a Pentium 4 with 2.8 $\mathrm{GB}$ processor. The following parameter values are used.

$\begin{array}{ll}a_{n l t} & \text { is uniformly drawn from [1, 3] } \\ b_{n} & \text { is uniformly drawn from [2, 4] } \\ c_{l t} & \text { is uniformly drawn from [2, 6] } \\ h_{l t} & \text { is uniformly drawn from }[2,6] \\ g_{l m} & \text { is uniformly drawn from }[2,5] \\ h_{l t m} & \text { is uniformly drawn from }[2,4] \\ \beta & =10\end{array}$

and $R_{n t}$ with regard to the size of the problem is generated randomly.

To validate the proposed evolving fuzzy predictor model, it is compared it with the ARMA model. The order of the ARMA model used is $(1,1)$ (i.e., ARMA $(1,1)$ ), and for the proposed evolving fuzzy predictor model $M F=2$, rules=32. Table 1 shows that the absolute error for the evolving fuzzy predictor model is less than that of the ARMA model.

\begin{tabular}{|c|c|c|}
\hline & Order & Absolute error \\
\hline EFP & $\mathrm{MF}=2$, rules $=32$ & less than 0.3 \\
\hline ARMA & $\mathrm{p}=1, \mathrm{q}=1$ & less than 0.5 \\
\hline
\end{tabular}

Table1: Comparison of results of the EFP model with the ARMA model

To evaluate the proposed hybrid tabu-SA algorithm, we compare our hybrid algorithm with optimal solution, SA method and tabu search algorithm. For simplicity it is assumed that the number of periods is 3 and the number of products is 2 in all of the instances. For each instance the algorithm is run 20 times, and the average costs are reported in tables 2 and 3.

Table 2 shows that the proposed heuristic solutions are optimal (or near optimal) in different problem instances. The average CPU time is less than or equal to 71 seconds for proposed hybrid algorithm (CPU times are in the seconds). However, the maximum average CPU time to obtain the optimal solutions is equal to 43143 seconds, and for problem instances 10 to 15 by a reasonable amount of time limit, LINGO cannot find the optimal solution, and the heuristic solutions in these problem instances are better than the best solutions obtained by LINGO.8.

Table 3 shows the comparison results between hybrid algorithm, SA method and tabu search algorithm. The procedure to obtain the initial solution and candidate move used in the SA method and tabu search algorithm are the same as the procedure used in the hybrid algorithm. It can be seen that the solution quality of hybrid algorithm is better than that in the SA algorithm and tabu search algorithm. 


\begin{tabular}{|ccccccccc|}
\hline \multirow{2}{*}{ No. } & \# Retailers & \# Suppliers & \multicolumn{2}{c}{ Optimal solution } & & \multicolumn{3}{c|}{ Hybrid algorithm } \\
\cline { 8 - 9 } \cline { 6 - 8 } & & & Cost & CPU time & & Cost & CPU time & Gap $(\%)$ \\
\hline 1 & 4 & 1 & 6918 & 74 & & 6918 & 1 & 0 \\
2 & 4 & 2 & 6042 & 147 & & 6042 & 1 & 0 \\
3 & 6 & 1 & 7512 & 264 & & 7512 & 3 & 0 \\
4 & 6 & 2 & 6852 & 596 & & 6852 & 4 & 0 \\
5 & 8 & 1 & 8006 & 4967 & & 8006 & 9 & 0 \\
6 & 8 & 2 & 7665 & 22867 & & 7665 & 12 & 0 \\
7 & 9 & 1 & 8483 & 20346 & & 8502 & 13 & 0.22 \\
8 & 9 & 2 & 8215 & 32251 & & 8251 & 15 & 0.44 \\
9 & 9 & 2 & 7834 & 43143 & & 7856 & 17 & 0.28 \\
10 & 11 & 2 & 9076 & 12 hours limit & & 8679 & 21 & -4.37 \\
11 & 13 & 2 & 10558 & 12 hours limit & & 10079 & 25 & -4.54 \\
12 & 20 & 3 & 15937 & 24 hours limit & & 15136 & 39 & -5.03 \\
13 & 30 & 3 & 24972 & 24 hours limit & & 23467 & 56 & -6.03 \\
14 & 40 & 5 & 34593 & 48 hours limit & & 32814 & 61 & -5.14 \\
15 & 50 & 6 & 42989 & 48 hours limit & 39981 & 71 & -7.00 \\
\hline
\end{tabular}

Gap(\%)=100*(Heuristic solution value - LINGO best solution value) / LINGO best solution value

Table 2: Comparison of results of the heuristic solution and the optimal solution

\begin{tabular}{|c|c|c|c|c|c|c|c|c|}
\hline \multirow[t]{2}{*}{ No. } & \multirow[t]{2}{*}{ \# Retailers } & \multirow[t]{2}{*}{ \# Suppliers } & \multicolumn{2}{|c|}{ Hybrid algorithm } & \multicolumn{2}{|c|}{ SA algorithm } & \multicolumn{2}{|c|}{ Tabu search algorithm } \\
\hline & & & Cost & CPU time & Cost & CPU time & Cost & CPU time \\
\hline 1 & 11 & 4 & 8679 & 21 & 8746 & 20 & 8751 & 21 \\
\hline 2 & 13 & 4 & 10079 & 25 & 10175 & 24 & 10202 & 25 \\
\hline 3 & 20 & 6 & 15136 & 39 & 15331 & 37 & 15414 & 38 \\
\hline 4 & 30 & 8 & 23467 & 56 & 23789 & 53 & 23931 & 55 \\
\hline 5 & 40 & 10 & 32814 & 61 & 33431 & 59 & 33668 & 61 \\
\hline 6 & 50 & 13 & 39981 & 71 & 40838 & 67 & 41179 & 70 \\
\hline 7 & 60 & 16 & 50213 & 79 & 51032 & 74 & 51518 & 76 \\
\hline 8 & 70 & 17 & 58976 & 88 & 60185 & 85 & 60752 & 86 \\
\hline 9 & 80 & 18 & 67198 & 98 & 68711 & 93 & 69316 & 95 \\
\hline 10 & 90 & 20 & 78623 & 107 & 80213 & 100 & 80910 & 103 \\
\hline 11 & 100 & 22 & 91472 & 116 & 93929 & 111 & 94716 & 115 \\
\hline 12 & 120 & 24 & 112038 & 131 & 115298 & 123 & 116234 & 128 \\
\hline 13 & 150 & 26 & 146342 & 155 & 150917 & 145 & 152009 & 149 \\
\hline 14 & 180 & 28 & 185894 & 184 & 192186 & 176 & 193558 & 179 \\
\hline 15 & 200 & 30 & 203673 & 202 & 210892 & 193 & 212459 & 198 \\
\hline
\end{tabular}

CPU times are in the seconds

Table 3: Comparison of results of the hybrid algorithm, the SA algorithm and the tabu search algorithm

\section{CONCLUSIONS AND DIRECTIONS FOR FUTURE RESEARCH}

This paper considers information flow in a three-echelon supply chain model with customer demands forecasting. To decrease the risk of the supply chain system, the customers' demands are predicted first and this prediction was used as an input to the supply chain model. An evolving fuzzy predictor (EFP) model was proposed to predict the customers' demands. Also for solving the supply chain model, a hybrid heuristic combining tabu search with simulated annealing (SA) sharing the same tabu list was developed. For validating, we compare the EFP model with the ARMA model and also compare the hybrid algorithm with the optimal solution, the SA algorithm and the tabu search algorithm. The results of computational tests indicate that the EFP model and hybrid algorithm are both effective and efficient for a wide variety of problem sizes. It is attractive to study the behavior with 
other information sharing modes or different inventory strategies can be incorporated into this supply chain model similarly. These are the potential directions for further research.

\section{REFERENCES}

[1] Gavirneni, S., Kapuscinski, R. and Tayur, S. 1999. Value of information in capacitated supply chains, Management Science, Vol. 45, pp 16-24.

[2] Lee, H.L., So, K.C. and Tang, C.S. 2000. The value of information sharing in a twolevel supply chain, Management Science, Vol. 46, pp 626-643.

[3] Cachon, G.P. and Fisher, M. 2000. Supply chain inventory management and the value of shared information, Management Science, Vol. 46, pp 1032-1048.

[4] Gavirneni, S. 2001. Benefits of co-operation in a production distribution environment, European Journal of Operational Research, Vol. 130, pp 612-622.

[5] Aviv, Y. and Federgruen, A. 1998. The operational benefits of information sharing and vendor management inventory programs, Working Paper.

[6] Cachon, G.P. and Lariviere, M.A. 2001. Contracting to assure supply: How to share demand forecasts in a supply chain, Management Science, Vol. 47, pp 629-646.

[7] Aviv, Y. 2001. The effect of collaborative forecasting on supply chain performance, Management Science, Vol. 47, pp 1326-1343.

[8] Zhao, X.D., Xie, J. and Leung, J. 2002. The impact of forecasting model selection on the value of information sharing in a supply chain, European Journal of Operational Research, Vol. 142, pp 321-344.

[9] Pourahmadi, M. 2001. Foundation of Time Series Analysis and Prediction Theory, John Willy \& Sons, Inc.

[10] Armstrong, J.S. 2001. Principles of forecasting: a handbook for researchers and practitioner, Norwell, Massachusetts, Kluwer Academic Publishers.

[11] Aburto, L. and Weber, R. 2007. Improved supply chain management based on hybrid demand forecasts, Applied Soft Computing, Vol. 7, pp 136-144.

[12] Acampora, G. and Loia, V. 2005. Using fuzzy technology in ambient intelligence environment, Proc. of IEEE International Conference on Fuzzy Systems, FUZZIEEE2005 Reno, NV, United States.

[13] Figueiredo, M. and Ballini, R. 2004. Learning algorithms for a class of neuro-fuzzy network and applications, IEEE Transactions on Systems, Man, and Cybernetics - Part C: Applications and Review, Vol.34, pp 293-301.

[14] Ishibuchi, H. and Yamamoto, T. 2005. Rule weight specification in fuzzy rule-based classification systems, IEEE Transactions on Fuzzy Systems, Vol.13, pp 428-435.

[15] Liang, Y. and Liang, X. 2006. Improving signal prediction performance of neural networks through multi-resolution learning approach, IEEE Transactions on Systems, Man, and Cybernetics-Part B: Cybernetics, Vol.36, pp 341-352.

[16] Angelov, P. 2002. Evolving Rule Based Models: A Tool for Design of Flexible Adaptive Systems, Physical-Verlag, Heidelberg.

[17] Chen, Y.M. and Lin, C-T. 2007. Dynamic parameter optimization of evolutionary 
computation for on-line prediction of time series with changing dynamics, Applied Soft Computing, Vol.7, pp 1170-1176.

[18] Kasabov, N. and Song, Q. 2002. DENFIS: dynamic evolving neural-fuzzy inference system and its application for time-series prediction, IEEE Transactions on Fuzzy Systems, Vol.10, pp 144-154.

[19] Makhoul, J. 1975. Linear prediction: A tutorial review, IEEE, pp 561-580.

[20] Brockwell, P. J. and Davis, R.A. 1987. Time Series: Theory and Methods, SpringerVerlag.

[21] Wang, J.S and Lee, G. 2002. Self-adaptive Neuro-Fuzzy Inference Systems for Classification Applications, IEEE Transactions on Fuzzy Systems, Vol.10, pp 86-98.

[22] Skiscim, C.C. and Golden, B.L. 1983. Optimization by simulated annealing: a preliminary computational study for the TSP. Winter Simulation Conference. 
http://sajie.journals.ac.za 